\title{
BMJ Open Psychological impact and recovery after involvement in a patient safety incident: a repeated measures analysis
}

\author{
Eva Van Gerven, ${ }^{1}$ Luk Bruyneel, ${ }^{1}$ Massimiliano Panella, ${ }^{2}$ Martin Euwema, ${ }^{3}$ \\ Walter Sermeus, ${ }^{1}$ Kris Vanhaecht ${ }^{1}$
}

To cite: Van Gerven E, Bruyneel L, Panella M, et al. Psychological impact and recovery after involvement in a patient safety incident: a repeated measures analysis. BMJ Open 2016;6:e011403. doi:10.1136/bmjopen-2016011403

- Prepublication history for this paper is available online. To view these files please visit the journal online (http://dx.doi.org/10.1136/ bmjopen-2016-011403).

Received 4 February 2016 Revised 26 May 2016 Accepted 3 August 2016

\section{CrossMark}

\footnotetext{
${ }^{1} \mathrm{KU}$ Leuven-University of Leuven Institute for Healthcare Policy, Leuven, Belgium

${ }^{2}$ Faculty of Medicine, University of Eastern Piedmont Amedeo Avogadro, Vercelli, Italy

${ }^{3} \mathrm{KU}$ Leuven-University of Leuven Occupational \& Organizational Psychology and Professional Learning, Leuven, Belgium
}

Correspondence to Dr Kris Vanhaecht; kris. vanhaecht@med.kuleuven.be

\section{ABSTRACT}

Objective: To examine individual, situational and organisational aspects that influence psychological impact and recovery of a patient safety incident on physicians, nurses and midwives.

Design: Cross-sectional, retrospective surveys of physicians, midwives and nurses.

Setting: 33 Belgian hospitals.

Participants: 913 clinicians (186 physicians, 682 nurses, 45 midwives) involved in a patient safety incident.

Main outcome measures: The Impact of Event Scale was used to retrospectively measure psychological impact of the safety incident at the time of the event and compare it with psychological impact at the time of the survey.

Results: Individual, situational as well as organisational aspects influenced psychological impact and recovery of a patient safety incident. Psychological impact is higher when the degree of harm for the patient is more severe, when healthcare professionals feel responsible for the incident and among female healthcare professionals. Impact of degree of harm differed across clinicians. Psychological impact is lower among more optimistic professionals. Overall, impact decreased significantly over time. This effect was more pronounced for women and for those who feel responsible for the incident. The longer ago the incident took place, the stronger impact had decreased. Also, higher psychological impact is related with the use of a more active coping and planning coping strategy, and is unrelated to support seeking coping strategies. Rendered support and a support culture reduce psychological impact, whereas a blame culture increases psychological impact. No associations were found with job experience and resilience of the health professional, the presence of a second victim support team or guideline and working in a learning culture.

Conclusions: Healthcare organisations should anticipate on providing their staff appropriate and timely support structures that are tailored to the healthcare professional involved in the incident and to the specific situation of the incident.

\section{INTRODUCTION}

Improving the work life of healthcare providers is increasingly seen as a critical aspect of
Strengths and limitations of this study

- This paper adds new knowledge on the factors associated with psychological distress resulting from involvement in patient safety incidents.

- This paper is one of the first to provide quantitative data on the recovery of second victims.

- This paper includes a timely question, a large population and the use of standardised and validated questionnaires.

- The study was not prospective but instead asked participants to think back and report on a past event, and then their current state which increases the chance that confounding might affect the observed associations.

- This study was limited to physicians, nurses and midwives, whereas other hospital workers may also be disturbed by stressful patient-related events.

optimising health system performance. This entails an expansion from the widely used triple aim-enhancing patient experiences, improving population health and reducing costs-to a quadruple aim. ${ }^{1}$ One element that has strong impact on the work life of healthcare providers is known as 'second victimhood'.2 Second victims are healthcare professionals who experience difficulties to cope with their emotions after a patient safety incident (PSI), medical error or adverse event. They are said to 'suffer in silence', and their emotional state has negative implications for patient safety and safety culture. $^{3-7}$

Surveys show that up to $50 \%$ of all hospital workers become a second victim at least once in their career. ${ }^{3}{ }^{4}$ Being involved in an incident can affect the quality of subsequent patient care to some extent. ${ }^{1-11}$ Second victims experience both a professional and personal impact. ${ }^{4} 5{ }^{5}$ They suffer, for example, from loss of self-confidence, fear of litigation or reputation damage, guilt, anger and fear. ${ }^{4813}$ Some studies find that the psychological impact of a PSI on healthcare 
professionals depends on the degree of harm for the patient, ${ }^{14}$ while other research shows that second victims experience similar reactions, no matter what happened. ${ }^{9}{ }^{16}$ Extant research shows that a number of other situational, individual and organisational factors may influence the impact of an incident. ${ }^{9}$ An important situational factor next to patient harm is the healthcare professional's sense of responsibility for the particular incident. Individual factors include gender, profession, experience, personal resources and coping strategies. The presence of a support team, protocol or guideline, organisational culture and forms of rendered support are the examples of organisational factors. Edrees and Federico ${ }^{3}$ recently expressed the need for research that investigates the relation with organisational culture.

It is of healthcare institutions' best interest to reduce the negative consequences of PSIs on healthcare professionals. Although many fail to do so effectively, ${ }^{7} 1718$ there are some organisations that have set a second victim support programme in place. ${ }^{3}{ }^{19-22}$ Currently, the mechanisms of such support programmes are however largely activated only when healthcare professionals already express second victim symptoms after having been involved in an incident. A missing element in managerial practice is to understand and anticipate on factors that are likely to influence the psychological impact and recovery from a PSI. Tailored and timely support would potentially buffer the likelihood of health professionals becoming second victims or guide the recovery process.

The aim of this study is to describe physicians', nurses' and midwives' psychological impact and recovery from a PSI and to examine which specific factors are likely to influence impact and recovery. Findings are for a multicenter study of physicians', nurses' and midwives' reports on the psychological impact of a PSI at the time of the incident and at the time of the survey. First, we determine which situational and individual aspects influence the psychological impact and the recovery process after involvement in a PSI. Second, we examine which organisational aspects, as perceived by healthcare professionals, reduce the psychological impact and stimulate the recovery process.

\section{METHODS}

\section{Hospital and healthcare professional samples}

An online survey of 24118 physicians, nurses and midwives in 33 Belgian hospitals was undertaken between May and December 2014. Hospitals were selected in two phases. First, we randomly selected 30 hospitals from a sample of all Flemish (Dutch-speaking) hospitals $(\mathrm{N}=156)$, proportionally stratified by hospital type (acute, psychiatric and rehabilitation hospitals) and size ( $<600$ beds is small, $>600$ beds is large). We sampled from each strata at the same rate. ${ }^{23} \mathrm{~A}$ total of 26 hospitals agreed to participate in the study $(87 \%$ response rate). In addition, seven hospitals that were not selected at random participated on a voluntary basis. An invitation email containing an embedded link to the survey was sent to all physicians $(\mathrm{N}=4696)$, nurses $(\mathrm{N}=18$ 441) and midwives $(\mathrm{N}=981)$ in these hospitals, for a total of 24118 invitees. Follow-up emails were sent after 2 and 4 weeks. Participation was voluntary and informed consent was assumed if the survey was completed. Ethical approval was obtained from the Ethics Committee of KU Leuven (ML10363).

Data included surveys of 1755 healthcare professionals (7\% response rate) of which 378 were physicians $(8 \%$ response rate), 1294 were nurses (7\% response rate) and 83 were midwives ( $8 \%$ response rate). The overall response rate varied from $1 \%$ to $35 \%$ at the hospital level. Response rates did not significantly differ between hospitals that were randomly selected or participated voluntarily. Out of 1755 respondents, 913 were still employed in the hospital where they had experienced their most memorable incident (important for associations with organisational culture) and fully completed the main instrument to measure psychological impact. Table 1 displays participants' demographic data and experiences with PSIs witnessed on the ward on the one hand and personally involved in on the other hand, within their entire career and within the past 12 months. Respondents elaborated on their most memorable incident and described what happened. Classification of PSIs was based on The Conceptual Framework for the International Classification for Patient Safety (2009). ${ }^{24}$ Incident type 'medication and intravenous fluids' was most common $(35.5 \%)$, followed by incidents within the clinical process or procedure $(34.4 \%)$ and patient or staff behaviour $(12 \%)$. See table 2 for more details.

\section{Key measures}

The survey included a number of demographic variables and an assessment of experiences with PSIs. A PSI is defined as 'an event or circumstance that could have resulted, or did result, in unnecessary harm to a patient..$^{24}$ Respondents were asked to answer 'yes' or 'no' to the question whether they had witnessed a PSI on the ward or had personally been involved in one, and this during two time frames-their entire career and the past 12 months. If a respondent indicated to have been involved in an incident, personally or on the ward, he or she was asked to describe the most memorable event.

Detailed information regarding this most memorable incident was captured using internationally validated scales and customised scales developed by the research team for the purpose of this study.

\section{Psychological impact}

The 15-item Impact of Event Scale (IES) ${ }^{25} 26$ was used to measure the psychological impact of the PSI. The IES is one of the most widely used self-report instruments designed to assess post-traumatic stress reactions. ${ }^{27}$ The IES is useful in following the trajectory of a person responding to a specific traumatic life event over a long period of time, since it can easily be used repetitively. ${ }^{26}$ We therefore used the IES to capture the impact of the 
Table 1 Demographic data and experiences with patient safety incidents

\begin{tabular}{|c|c|c|c|c|c|c|c|c|c|}
\hline & \multirow{3}{*}{$\begin{array}{l}\text { Total } \\
\mathbf{n}\end{array}$} & \multicolumn{4}{|c|}{$\begin{array}{l}\text { Witnessed a patient safety incident on } \\
\text { the ward }\end{array}$} & \multicolumn{4}{|c|}{$\begin{array}{l}\text { Personally involved in a patient safety } \\
\text { incident }\end{array}$} \\
\hline & & \multicolumn{2}{|c|}{$\begin{array}{l}\text { Within entire } \\
\text { career }\end{array}$} & \multicolumn{2}{|c|}{$\begin{array}{l}\text { Within the past } \\
12 \text { months }\end{array}$} & \multicolumn{2}{|c|}{$\begin{array}{l}\text { Within entire } \\
\text { career }\end{array}$} & \multicolumn{2}{|c|}{$\begin{array}{l}\text { Within the past } \\
12 \text { months }\end{array}$} \\
\hline & & $\mathrm{n}$ & Per cent & $\bar{n}$ & Per cent & $\mathrm{n}$ & Per cent & $\mathrm{n}$ & Per cent \\
\hline Total & 913 & 913 & 100 & 697 & 76.3 & 762 & 83.5 & 348 & 38.1 \\
\hline \multicolumn{10}{|l|}{ Type of hospital } \\
\hline Acute & 772 & 770 & 84.3 & 581 & 63.6 & 643 & 70.4 & 287 & 31.4 \\
\hline Psychiatric & 113 & 113 & 12.4 & 96 & 10.5 & 105 & 11.5 & 55 & 6.0 \\
\hline Rehabilitation & 28 & 27 & 3.0 & 20 & 2.2 & 14 & 1.5 & 6 & 0.7 \\
\hline \multicolumn{10}{|l|}{ Age } \\
\hline$<25$ years & 40 & 40 & 4.4 & 36 & 3.9 & 28 & 3.1 & 21 & 2.3 \\
\hline 25-34 years & 186 & 186 & 20.4 & 161 & 17.6 & 159 & 17.4 & 83 & 9.1 \\
\hline $35-44$ years & 247 & 247 & 27.1 & 194 & 21.2 & 211 & 23.1 & 10 & 1.1 \\
\hline $45-54$ years & 304 & 303 & 33.2 & 215 & 23.5 & 245 & 26.8 & 98 & 10.7 \\
\hline$>54$ years & 136 & 134 & 14.7 & 91 & 10.0 & 119 & 13.0 & 45 & 4.9 \\
\hline \multicolumn{10}{|l|}{ Gender } \\
\hline Male & 253 & 253 & 27.7 & 194 & 21.2 & 217 & 23.8 & 100 & 11.0 \\
\hline Female & 660 & 657 & 72.0 & 503 & 55.1 & 545 & 59.7 & 248 & 27.2 \\
\hline \multicolumn{10}{|l|}{ Profession } \\
\hline Physician & 186 & 186 & 20.4 & 127 & 13.9 & 165 & 18.1 & 78 & 8.5 \\
\hline Nurse & 682 & 679 & 74.4 & 531 & 58.1 & 561 & 61.4 & 252 & 27.6 \\
\hline Midwife & 45 & 45 & 4.9 & 39 & 4.3 & 36 & 3.9 & 18 & 2.0 \\
\hline \multicolumn{10}{|l|}{ Experience } \\
\hline$<6$ months & 3 & 3 & 0.3 & 1 & 0.1 & 2 & 0.2 & 1 & 0.1 \\
\hline 6 months -1 year & 15 & 15 & 1.6 & 15 & 1.6 & 9 & 1.0 & 10 & 1.1 \\
\hline $1-3$ years & 43 & 43 & 4.7 & 38 & 4.2 & 28 & 3.1 & 19 & 2.1 \\
\hline $3-5$ years & 71 & 71 & 7.8 & 67 & 7.3 & 61 & 6.7 & 36 & 3.9 \\
\hline $5-10$ years & 101 & 101 & 11.1 & 82 & 9.0 & 88 & 9.6 & 46 & 5.0 \\
\hline $10-15$ years & 137 & 137 & 15.0 & 108 & 11.8 & 122 & 13.4 & 49 & 5.4 \\
\hline $15-20$ years & 116 & 116 & 12.7 & 93 & 10.2 & 97 & 10.6 & 46 & 5.0 \\
\hline$>20$ years & 389 & 386 & 42.3 & 263 & 28.8 & 323 & 35.4 & 126 & 13.8 \\
\hline \multicolumn{10}{|l|}{ In training } \\
\hline No & 875 & 872 & 95.5 & 667 & 73.1 & 730 & 80.0 & 333 & 36.5 \\
\hline Yes & 38 & 38 & 4.2 & 30 & 3.3 & 32 & 3.5 & 15 & 1.6 \\
\hline \multicolumn{10}{|c|}{ Management position } \\
\hline No & 571 & 568 & 64.9 & 435 & 51.8 & 471 & 53.8 & 213 & 24.3 \\
\hline Yes & 304 & 304 & 34.7 & 232 & 26.5 & 259 & 29.6 & 120 & 13.7 \\
\hline
\end{tabular}

most memorable adverse event at two points in time: a retrospective measure of impact at the time of the incident and a measure of impact at the time of the survey. Example items include, 'I thought about it when I didn't mean to' and 'I tried not to talk about it'. IES response categories are 'not at all', 'rarely', 'sometimes' and 'often', and are coded as 0, 1, 3 and 5, respectively. From an overall sum score between 0 and 75 , several cut-off points on this continuum have been suggested in the literature to distinguish potential post-traumatic stress disorder (PTSD) cases from non-cases. ${ }^{28}$ An overall IES score of $\geq 19$ is considered the most appropriate screener for the prediction of PTSD; ${ }^{27} 2930$ however, in this study we apply the IES score as a continuous variable.

\section{Situational factors}

Respondents were asked to answer 'yes' or 'no' to the question whether they felt personally responsible for the (most memorable) PSI and whether this happened in the hospital where they are currently working. To indicate the time since the event, options were given from 'less than 3 months ago' to 'more than 20 years ago'. Degree of harm indicates the patient outcome due to the PSI. Response categories were 'none' (thus a no harm incident or near miss), 'mild', 'moderate', 'severe' or 'death of the patient'.

\section{Individual factors}

Demographic variables included gender, profession and professional experience. To indicate professional experience, response options were from 'less than 6 months' to 'more than 20 years'.

To measure coping skills after being involved in an adverse event, the Brief Committee on Publication Ethics (COPE) ${ }^{31}$ was used. The Brief COPE is a shortened form of the COPE inventory ${ }^{32}$ and consists of 16 
Table 2 Type of most memorable patient safety incident experienced by participants

\begin{tabular}{lll}
\hline Type of patient safety incident & n & Per cent \\
\hline Medication/intravenous fluids & 324 & 35.5 \\
Clinical process/procedure & 314 & 34.4 \\
Staff/patient behaviour & 110 & 12 \\
Patient accidents eg, falls & 70 & 7.7 \\
Blood/blood products & 32 & 3.5 \\
Clinical administration & 17 & 1.9 \\
Medical device/equipment & 10 & 1.1 \\
Nutrition & 9 & 1 \\
Oxygen/gas/vapour & 7 & 0.8 \\
Infrastructure/building/fixtures & 4 & 0.4 \\
Resources/organisational management & 3 & 0.3 \\
Documentation & 2 & 0.2 \\
Unclear & 11 & 1.2 \\
\hline
\end{tabular}

items that measure different behaviours and cognitive activities one might engage in coping with stress. An example item is 'I take action to try to make the situation better'. In the current study, respondents were asked to rate each item on a 5-point scale anchored between (almost) never and (almost) always, to indicate the degree to which they typically used each strategy to deal with stress after an adverse event.

Personal resources such as self-efficacy, resilience and optimism were assessed by eight items. These items are work adjusted and shortened from the Life Orientation Test (LOT) ${ }^{33}$ Sample items are 'I can always manage to solve difficult problems at work if I try hard enough' and 'With respect to my work, I always look on the bright side'. The participants answered using a five-point Likert scale (1: 'strongly disagree' to 5: 'strongly agree').

\section{Organisational factors}

A hospital-level measure of availability of a peer support team or support protocol was surveyed by a yes or no question from the hospital contact persons. ${ }^{17}$

To measure the support received in the aftermath of the PSI, we included items from prior qualitative studies by our research team (own unpublished work). Participants were asked to score the following items: 'I received information on what happened and how this could happen', 'I received information on what to do next and what would happen next (for me, for the patient, for the hospital)' and 'I received extra guidance at the workplace'. Respondents were asked to score these items on a 4-point scale: 'not applicable', 'no', 'partially', 'yes'. ${ }^{24}$

Organisational culture was surveyed by eight items of the Hospital Survey on Patient Safety Culture, ${ }^{34} 35$ which examines patient safety culture from a hospital staff perspective. Respondents were asked to rate each item on a 5-point scale (1: 'strongly disagree' to 5: 'strongly agree'). An example item is 'Staff feels like their mistakes are held against them'.
Analysis

We first evaluated measurement invariance ${ }^{36}$ of the IES factor solution across participant's retrospective responses on psychological impact at the time of the incident and at the time of the survey. We applied progressively more stringent constraints in multiple group confirmatory factor analysis ${ }^{36} 37$ using Mplus 7.1. A onedimensional solution including all 15 IES items showed evidence of configural (invariant factor loading pattern), metric (invariant factor loadings) and scalar invariance (invariant factor intercepts) of the factor solution, which means that IES scores can be compared across time points. ${ }^{38}$

Second, we used SAS software version 9.4 to fit a series of multilevel models for IES repeated measures on healthcare workers nested in hospitals. ${ }^{39}$ A first model included only time as an explanatory variable to examine recovery in psychological impact. Second, the effect of situational, individual and organisational aspects on overall psychological impact and recovery was examined for each aspect separately. Only aspects showing statistical significance on psychological impact and/or recovery were retained for further analysis. Third, we examined which situational and individual aspects jointly influence overall psychological impact and recovery. Fourth, we explored which organisational aspects, as perceived by healthcare professionals, are jointly associated with overall psychological impact and recovery, while controlling for statistically significant situational and individual aspects.

\section{RESULTS}

\section{Psychological impact and recovery after a PSI}

The overall mean IES score for all participants was 17.72 at the time of the incident and 8.99 at the time of the survey. There was a significant decrease in IES scores between the retrospectively measured score and the score at the time of the survey.

\section{Situational factors, individual factors and psychological impact}

The significant decrease in IES scores remained after adjusting for all other fixed effects of situational and individual factors in the model $(\beta=-15.07, \mathrm{p}<0.0001)$.

Table 3 shows that PSIs resulting in moderate harm $(\beta=6.75, p=0.0001)$, severe harm $(\beta=10.69, p<0.0001)$ or death $(\beta=9.78, \mathrm{p}<0.0001)$ are systematically associated with higher psychological impact on the health professional compared with incidents that do not result in harm for the patient. On the other hand, with increasing harm (moderate: $\beta=-5.94, \mathrm{p}<0.0001$; severe: $\beta=-4.95, \quad p=0.0059$; death: $\beta=-6.30, \quad p<0.0001)$, the decrease in IES score also tends to be stronger. Descriptive findings suggested further exploration across professional groups. As such, we tested for differences across nurses and physicians for each combination of levels of time and degree of harm. Midwives could not 
Table 3 Individual and situational characteristics and Impact of Event Scale score: descriptive findings and findings from repeated measures analyses

\begin{tabular}{|c|c|c|c|c|c|c|c|c|}
\hline & \multirow[b]{3}{*}{$\mathbf{n}$} & \multicolumn{3}{|c|}{ IES score } & \multicolumn{4}{|c|}{$\begin{array}{l}\text { Multiple model for individual and situational } \\
\text { characteristics jointly }\end{array}$} \\
\hline & & \multirow[t]{2}{*}{ Then } & \multirow[t]{2}{*}{ Now } & \multirow[t]{2}{*}{ Mean } & \multicolumn{2}{|l|}{ Main effect } & \multicolumn{2}{|l|}{$X$ time } \\
\hline & & & & & Estimate (SE) & p Value & Estimate (SE) & p Value \\
\hline Intercept & & & & & $20.06(5.12)$ & 0.0005 & & \\
\hline Time & & 17.72 & 8.99 & 13.36 & $-15.07(3.54)$ & $<0.0001$ & & \\
\hline \multicolumn{9}{|l|}{ Situational characteristics } \\
\hline \multicolumn{9}{|l|}{ Level of harm for patient } \\
\hline None & 182 & 13.55 & 8.46 & 11.01 & 0 & & 0 & \\
\hline Mild & 216 & 15.01 & 7.43 & 11.22 & $1.57(1.75)$ & 0.3671 & $-2.45(1.34)$ & 0.0682 \\
\hline Moderate & 208 & 19.11 & 8.55 & 13.83 & $6.75(1.77)$ & 0.0001 & $-5.94(1.36)$ & $<0.0001$ \\
\hline Severe & 81 & 22.27 & 12.23 & 17.25 & $10.69(2.33)$ & $<0.0001$ & $-4.95(1.79)$ & 0.0059 \\
\hline Death & 226 & 20.74 & 10.14 & 15.44 & $9.78(1.79)$ & $<0.0001$ & $-6.30(1.37)$ & $<0.0001$ \\
\hline \multicolumn{9}{|l|}{ Time of incident } \\
\hline$<3$ months ago & 78 & 12.91 & 11.26 & 12.08 & $-4.87(3.08)$ & 0.1134 & $9.88(2.36)$ & $<0.0001$ \\
\hline $3-6$ months ago & 62 & 11.98 & 8.68 & 10.33 & $-1.76(2.99)$ & 0.0369 & 9.35 (2.49) & 0.0002 \\
\hline 6 months -1 year ago & 83 & 16.36 & 10.98 & 13.67 & $-2.22(3.00)$ & 0.4603 & $6.60(2.31)$ & 0.0043 \\
\hline $1-3$ years ago & 204 & 17.11 & 9.05 & 13.08 & $-3.71(2.60)$ & 0.1547 & $5.15(2.00)$ & 0.0101 \\
\hline $3-5$ years ago & 110 & 17.62 & 7.77 & 12.70 & $-4.88(2.84)$ & 0.0860 & $4.41(2.19)$ & 0.0440 \\
\hline $5-10$ years ago & 140 & 20.39 & 9.11 & 14.75 & $-1.03(2.71)$ & 0.7036 & $2.56(2.08)$ & 0.2186 \\
\hline $10-15$ years ago & 106 & 20.61 & 8.08 & 14.34 & $-1.07(2.78)$ & 0.6995 & $0.85(2.14)$ & 0.6899 \\
\hline $15-20$ years ago & 70 & 20.44 & 8.16 & 14.30 & $-0.85(3.02)$ & 0.7779 & $1.10(2.32)$ & 0.6358 \\
\hline$>20$ years ago & 59 & 19.59 & 7.56 & 13.58 & 0 & & 0 & \\
\hline \multicolumn{9}{|l|}{ Sense of responsibility } \\
\hline No & 464 & 13.92 & 7.64 & 10.78 & 0 & & 0 & \\
\hline Yes & 449 & 21.63 & 10.38 & 16.01 & $7.43(1.18)$ & $<0.0001$ & $-4.44(0.91)$ & $<0.0001$ \\
\hline \multicolumn{9}{|l|}{ Individual characteristics } \\
\hline \multicolumn{9}{|l|}{ Personal characteristics } \\
\hline \multicolumn{9}{|l|}{ Gender } \\
\hline Male & 253 & 15.34 & 7.87 & 11.60 & $-5.61(1.35)$ & $<0.0001$ & $3.93(1.03)$ & 0.0001 \\
\hline Female & 660 & 18.63 & 9.41 & 14.02 & 0 & & 0 & \\
\hline \multicolumn{9}{|l|}{ Profession } \\
\hline Physician & 186 & 20.17 & 9.17 & 14.67 & $-0.38(2.90)$ & 0.8951 & $-0.71(2.22)$ & 0.7491 \\
\hline Nurse & 682 & 16.85 & 8.82 & 12.84 & $-2.79(2.65)$ & 0.2928 & $2.15(2.03)$ & 0.2898 \\
\hline Midwife & 45 & 20.64 & 10.76 & 15.70 & 0 & & 0 & \\
\hline \multicolumn{9}{|l|}{ Experience } \\
\hline$<6$ months & 3 & 28.33 & 23.00 & 25.67 & $-^{*}$ & - & - & - \\
\hline 6 months- 1 year & 15 & 10.13 & 4.80 & 7.47 & - & - & - & - \\
\hline $1-3$ years & 43 & 11.21 & 5.74 & 8.48 & - & - & - & - \\
\hline $3-5$ years & 71 & 15.96 & 8.75 & 12.35 & - & - & - & - \\
\hline $5-10$ years & 101 & 18.35 & 8.42 & 13.38 & - & - & - & - \\
\hline $10-15$ years & 137 & 18.29 & 8.89 & 13.59 & - & - & - & - \\
\hline $15-20$ years & 116 & 17.80 & 9.36 & 13.58 & - & - & - & - \\
\hline$>20$ years & 389 & 18.96 & 9.63 & 14.30 & - & - & - & - \\
\hline Personal resources & & & & & & & & \\
\hline Self-efficacy & & & & & & & & \\
\hline Low & 39 & 23.33 & 9.44 & 16.38 & 0 & & 0 & \\
\hline Average & 604 & 18.80 & 9.46 & 14.13 & $-2.70(2.64)$ & 0.3070 & $3.67(2.03)$ & 0.0705 \\
\hline High & 114 & 16.21 & 8.65 & 12.43 & $-4.51(3.09)$ & 0.1459 & 5.47 (2.38) & 0.0215 \\
\hline Resilience & & & & & & & & \\
\hline Low & 24 & 19.88 & 9.79 & 14.83 & $-^{*}$ & - & - & - \\
\hline Average & 500 & 19.37 & 10.10 & 14.74 & - & - & - & - \\
\hline High & 233 & 16.97 & 7.64 & 12.30 & - & - & - & - \\
\hline Optimism & & & & & & & & \\
\hline Low & 95 & 26.37 & 13.42 & 19.89 & 0 & & 0 & \\
\hline Average & 523 & 17.80 & 9.10 & 13.45 & $-6.52(1.80)$ & 0.0003 & $2.76(1.38)$ & 0.0467 \\
\hline High & 139 & 16.55 & 7.42 & 11.99 & $-7.13(2.26)$ & 0.0016 & $1.48(1.74)$ & 0.0571 \\
\hline
\end{tabular}


Table 3 Continued

\begin{tabular}{|c|c|c|c|c|c|c|c|c|}
\hline & \multirow[b]{3}{*}{$\mathbf{n}$} & \multicolumn{3}{|c|}{ IES score } & \multicolumn{4}{|c|}{$\begin{array}{l}\text { Multiple model for individual and situational } \\
\text { characteristics jointly }\end{array}$} \\
\hline & & \multirow[t]{2}{*}{ Then } & \multirow[t]{2}{*}{ Now } & \multirow[t]{2}{*}{ Mean } & \multicolumn{2}{|l|}{ Main effect } & \multicolumn{2}{|l|}{$X$ time } \\
\hline & & & & & Estimate (SE) & p Value & Estimate (SE) & p Value \\
\hline \multicolumn{9}{|c|}{ Coping strategies } \\
\hline \multicolumn{9}{|c|}{ Support seeking } \\
\hline Low† & 473 & 17.61 & 9.37 & 13.49 & $-^{\star}$ & - & - & - \\
\hline High & 440 & 17.83 & 8.58 & 13.20 & - & - & - & - \\
\hline \multicolumn{9}{|c|}{ Active coping and planning } \\
\hline Low† & 518 & 15.09 & 7.69 & 11.39 & 0 & & 0 & \\
\hline High & 395 & 21.15 & 10.69 & 15.92 & $4.62(1.15)$ & $<0.0001$ & $-1.68(0.88)$ & 0.0571 \\
\hline
\end{tabular}

be included in this specific analysis because of the low number of participants. Overall, when patients had died after the occurrence of a PSI, nurses' remaining psychological impact at the time of the survey was significantly higher than that of physicians $(\mathrm{F}$ value $=4.91, \mathrm{p}=0.0268$ ). Physicians retrospectively measured scores were higher than those of nurses when patients experienced moderate harm after the occurrence of a PSI $(\mathrm{F}=7.08$, $\mathrm{p}=0.0079$ ). For all other combinations of levels of time and consequence of the event, there was no significant difference among these professional groups.

Generally speaking, the longer ago the incident took place, the stronger the IES score had decreased between the retrospectively measured score and the score at the time of the survey. Feeling personally responsible for the incident is associated with a higher overall IES score $(\beta=7.43, p<0.0001)$, but the psychological impact among those who indicated a sense of responsibility has decreased significantly more $(\beta=-4.44, \mathrm{p}<0.0001)$, indicating a stronger recovery process. Female healthcare professionals experience a significantly higher impact after a PSI than males $(\beta=5.61, \mathrm{p}<0.0001)$, but again the recovery is stronger $(\beta=-3.93, p=0.0001)$. The use of personal resources, such as optimism (average: $\beta=-6.52$, $\mathrm{p}=0.0003$; high: $\beta=-7.13, \mathrm{p}=0.0016$ ), has a significantly negative association with psychological impact. Highly self-efficient respondents experience a slower recovery $(\beta=5.47, p=0.0215)$. There was no association between the resilience of the health professional and the psychological impact nor recovery from a PSI. Respondents who use active coping and planning strategies tend to experience a significantly higher psychological impact $(\beta=4.62, p<0.0001)$.

\section{Organisational strategies to reduce the psychological impact and stimulate the recovery process}

In total, 11 hospitals reported having a support team for second victims in place and 14 hospitals reported having a support protocol at their disposal. Descriptive results in table 4 indicate that these do not influence psychological impact or recovery, which was confirmed in regression analysis. The rendered support and organisational culture do however have an effect on the psychological impact of the incident. Respondents scoring the organisational culture above median as one of support and respect, experience a lower psychological impact $(\beta=-3.98, p=0.0012)$. Respondents scoring the organisational culture above median as one characterised by blame, experience a higher psychological impact $(\beta=3.39, p=0.0036)$. Support under the form of information concerning what happened $(\beta=-6.16, p=0.0027)$, information concerning what to do after the incident $(\beta=-4.77, p=0.0072)$ and extra guidance at the workplace $(\beta=4.61, p=0.0387)$ are all associated with significantly lower IES scores only when it was fully received, not when it was only partially received. No significant associations were found between these organisational strategies and recovery.

\section{DISCUSSION}

In this multicentre study, we examined the impact of individual, situational and organisational aspects on psychological impact and recovery of a PSI on clinicians. Psychological impact significantly decreases between the time of the incident and the time of the survey. Situational characteristics that influence the impact are sense of responsibility and degree of harm. Severe harm leaves the biggest impact, more so than death of the patient. Individual characteristics also influence the impact. Women, users of an active coping and planning strategy and respondents who score low on optimism, experience a higher impact. The fact that women react more strongly is in line with other studies. ${ }^{4} 14 \quad 164041$ Also in general psychology women tend to react stronger to stress situations. ${ }^{26}$ On the other hand, women show a better evolution between the retrospective measure of impact and impact at the time of the survey. No effect 
Table 4 Organisational characteristics and Impact of Event Scale score: descriptive findings and findings from repeated measures analyses

\begin{tabular}{|c|c|c|c|c|c|c|c|c|}
\hline & \multirow{2}{*}{\multicolumn{4}{|c|}{ IES score }} & \multicolumn{4}{|c|}{ Multiple model for organisational characteristics } \\
\hline & & & & & \multicolumn{2}{|c|}{ Main effect } & \multicolumn{2}{|l|}{$\mathrm{X}$ time } \\
\hline & n & Then & Now & Mean & Estimate (SE) & $\mathrm{p}$ Value & Estimate (SE) & p Value \\
\hline \multicolumn{9}{|c|}{ Support team/protocol } \\
\hline \multicolumn{9}{|c|}{ Support team available } \\
\hline No & 682 & 17.51 & 8.89 & 13.20 & $-{ }^{*}$ & - & - & - \\
\hline Yes & 231 (=11 org.) & 18.33 & 9.26 & 13.80 & - & - & - & - \\
\hline \multicolumn{9}{|c|}{ Protocol or guideline available } \\
\hline No & 619 & 17.47 & 9.05 & 13.26 & $-^{*}$ & - & - & - \\
\hline Yes & 294 (=14 org.) & 18.24 & 8.86 & 13.55 & - & - & - & - \\
\hline \multicolumn{9}{|l|}{ Culture } \\
\hline \multicolumn{9}{|c|}{ Culture of support and respect } \\
\hline Low† & 633 & 18.66 & 9.86 & 14.26 & 0 & & 0 & \\
\hline High & 280 & 15.58 & 7.02 & 11.30 & $-3.98(1.23)$ & 0.0012 & $0.78(0.96)$ & 0.4167 \\
\hline \multicolumn{9}{|l|}{ Learning culture } \\
\hline Low† & 675 & 18.09 & 9.43 & 13.76 & $-{ }^{*}$ & - & - & - \\
\hline High & 238 & 16.66 & 7.72 & 12.19 & - & - & - & - \\
\hline \multicolumn{9}{|l|}{ Blame culture } \\
\hline Low† & 580 & 15.62 & 7.64 & 11.63 & 0 & & 0 & \\
\hline High & 333 & 21.37 & 11.34 & 16.35 & $3.39(1.16)$ & 0.0036 & $-0.89(0.91)$ & 0.3257 \\
\hline \multicolumn{9}{|c|}{ Support received } \\
\hline \multicolumn{9}{|c|}{ Information concerning what happened } \\
\hline Not applicable & 108 & 8.87 & 5.94 & 7.41 & - & & - & \\
\hline No & 74 & 25.24 & 14.41 & 19.82 & 0 & & 0 & \\
\hline Partly & 154 & 24.73 & 11.90 & 18.32 & $-1.93(2.23)$ & 0.3876 & $-0.47(1.77)$ & 0.7890 \\
\hline Yes & 450 & 17.74 & 8.48 & 13.11 & $-6.16(2.05)$ & 0.0027 & $1.65(1.62)$ & 0.3088 \\
\hline \multicolumn{9}{|c|}{ Information concerning what to do } \\
\hline Not applicable & 134 & 10.51 & 5.72 & 8.12 & - & & - & \\
\hline No & 117 & 24.77 & 12.97 & 18.87 & 0 & & 0 & \\
\hline Partly & 155 & 22.67 & 11.03 & 16.85 & $-2.10(1.93)$ & 0.2778 & $0.33(1.53)$ & 0.8296 \\
\hline Yes & 380 & 17.88 & 8.84 & 13.36 & $-4.77(1.77)$ & 0.0072 & $2.42(1.40)$ & 0.0841 \\
\hline \multicolumn{9}{|c|}{ Extra guidance at the workplace } \\
\hline Not applicable & 418 & 14.80 & 6.82 & 10.81 & - & & - & \\
\hline No & 194 & 24.51 & 12.99 & 18.75 & 0 & & 0 & \\
\hline Partly & 80 & 25.28 & 13.20 & 19.24 & $-1.52(2.25)$ & 0.4977 & 0.28 (1.79) & 0.8761 \\
\hline Yes & 93 & 17.78 & 10.00 & 13.89 & $-4.61(2.22)$ & 0.0387 & $2.06(1.76)$ & 0.2438 \\
\hline
\end{tabular}


was found for resilience of the health professional. Resilience is considered key to sustainability of the healthcare workforce ${ }^{42}$ and therefore in theory highly important after involvement in a PSI. Further research will be needed to investigate the importance of resilience. In most research the impact of PSIs are studied among either nurses ${ }^{43-45}$ or physicians. ${ }^{3} 1416{ }^{46}$ In this study, we compared the IES scores from both professions and noticed that nurses react the way one would arguably suspect: they experience the biggest impact after an incident that results in death, followed by incidents with severe, moderate, mild and no harm. Physicians experience the biggest impact after an incident with severe harm, followed by moderate harm, death, mild and no harm. This can be explained by the nature of the work of physicians and their ultimate responsibility for the patient. ${ }^{47}$ There is however also disagreement in the literature as to whether the impact depends on the severity of the event ${ }^{14}{ }^{15}$ or whether second victims experience similar reactions, no matter what happened. ${ }^{9}{ }^{16}$ Organisational aspects included measures of support teams and protocols, culture and support received. The percentage of hospitals in this study (14 out of 33 hospitals) that claim to have a support protocol in place is comparable with previous research. ${ }^{17}$ There was no association between having an organisational peer support programme or guideline in place and the impact of and recovery from the event. One would tend to conclude that organisational support systems or protocols are of no use, yet previous research has shown that not all organisations that report to have a support programme in place, actually have one. ${ }^{17} \mathrm{In}$ the USA and the UK, several programmes have been set up to support second victims, ${ }^{5} 202249$ which are considered (but not proven) useful. ${ }^{20}$ Further research on this matter is urgently needed. A blame culture, in contradiction to a culture of support and respect, is devastating for the psychological impact of a PSI on clinicians. Leaders should teach staff how to investigate and debrief following a PSI in a way that does not incur blame, by cultivating an environment of performance improvement instead of punishment to prevent blame-related distress. ${ }^{50}$ Support in the form of information on what exactly happened, information on what to do next and extra guidance in the workplace has a positive association with the impact of the incident. When respondents fully agree that they have received the previously discussed forms of organisational support, only then is there a significant difference in IES scores. Partial support does not meet the needs of second victims. These results add to the list of other helpful support initiatives such as talking to peers ${ }^{18}$ or non-judgmental colleagues. $^{9}$

Other factors may have contributed to the impact of and recovery from the incident, such as patient characteristics (eg, demographics, procedures, diagnoses) or incident characteristics (eg, origin, discovery, reporting, legal consequences). ${ }^{24} 47$ Mitigating factors such as apologies to the patient, effective communication from staff and leaders, and effective protocols were not investigated. ${ }^{17}{ }^{24}$ Also, whereas this study was limited to a survey among physicians, nurses and midwives, studies with sufficiently large sample size should be designed to obtain information from other hospital workers, such as pharmacists, who may also be disturbed by stressful patient-related events. Although the type of the most memorable event was clear, it was unclear if this was the first major incident, or an event reflecting an accumulation of previous incidents or near misses. It is unknown how this affects impact and recovery, and personal resources and coping strategies. Owing to the low response rate, we have to recognise that we can only estimate the minimal prevalence rate of experiences with PSIs. Since no post hoc diagnosis of findings could be performed, it is unclear whether non-response bias occurred. The main interest is however not in describing prevalence or in the comparison of organisations-for which possible non-response would clearly be a threatbut in estimating associations between psychological impact and several factors. It seems unlikely that scores for those who did not respond would alter the direction or magnitude of this association much, as our sample consists of nurses, physicians and midwives with very different demographic characteristics and various degrees of psychological impact. On the other hand, nonresponse bias may have occurred particularly in our comparison of findings across physicians, nurses and midwives. The low response rate can be due to increased response burden or because it is still considered a taboo subject. Although we cannot be sure of causality because the data are cross sectional, two time periods were embedded into the questionnaire which allowed us to analyse the data as if they were longitudinal. Unmeasured distress could have occurred between the two time periods and influence psychological impact at the time of the survey. Therefore results of this study should be interpreted as associations rather than causation. Also, we have to be aware that participants may have exaggerated or minimised the incident (recall bias). However, looking at the evolution of the IES scores over time, table 3 shows a logical and progressive decrease of the IES score with more time that has passed since the incident. This supports the contention that respondents were able to reproduce the factual impact of the event over time. Serembus and colleagues describe that the memory of error stays with professionals for many years, often in high detail. ${ }^{52}$ It can be difficult for respondents to distinguish PSIs from adverse reactions ('unexpected harm resulting from a justified action where the correct process was followed for the context in which the event occurred' (ref. ${ }^{24}$, p. 23)). To prevent these from being included, all descriptions of the most memorable events were checked and non-PSIs (eg, work accidents, needle stick injuries) were deleted from the study sample. It is plausible that adverse reactions and near misses can trigger the same emotions as PSIs, which 
needs further research. In our analysis, we corrected for time since the incident, type of hospital, gender, profession and experience. However, some potential confounding variables could not be evaluated, such as the health of the respondent at the time of completion.

Proactive and reactive actions supported by the organisation and its leadership are needed to reduce the severity of the psychological impact of PSIs and markedly speed clinicians' healing process. Starting at the recruitment stage, effective screening should be routinely conducted to identify clinicians at risk, assessing personal resources and coping strategies that were found to affect impact and recovery in this study. Junior clinicians should be made familiar with the topic of second victims. They should have the opportunity to openly discuss PSIs as well as near misses with senior clinicians acting as coaches. These peer review meetings should take place routinely rather than only being incident based, provide clear information concerning what happened and what to do, acknowledge learning opportunities and be non-confrontational.

Twitter Follow Kris Vanhaecht at @krisvanhaecht

Collaborators Emmanuel Lesaffre.

Contributors EVG and LB contributed equally to this paper. The manuscript has been read and approved by all authors. All persons listed as authors have contributed to preparing the manuscript and the International Committee of Medical Journal Editors (ICMJE) criteria for authorship have been met (see table below):

- Substantial contributions to the conception or design of the work or the acquisition, analysis, or interpretation of data for the work; and

- Drafting the work or revising it critically for important intellectual content; and

- Final approval of the version to be published; and

- Agreement to be accountable for all aspects of the work in ensuring that questions related to the accuracy or integrity of any part of the work are appropriately investigated and resolved.

\begin{tabular}{|c|c|c|c|c|c|c|c|}
\hline \multirow[b]{2}{*}{ Authors } & \multicolumn{3}{|l|}{ Criteria 1} & \multicolumn{2}{|l|}{ Criteria 2} & \multicolumn{2}{|l|}{ Criteria 3} \\
\hline & $\begin{array}{l}\text { Conception } \\
\text { and design }\end{array}$ & $\begin{array}{l}\text { Acquisition } \\
\text { of } \\
\text { data }\end{array}$ & $\begin{array}{l}\text { Analysis } \\
\text { and } \\
\text { interpretation } \\
\text { of data }\end{array}$ & Drafting & Revising & Approval & $\begin{array}{l}\text { Agreement } \\
\text { for } \\
\text { accountability }\end{array}$ \\
\hline EVG & $x$ & $x$ & $\mathrm{x}$ & $x$ & $x$ & $x$ & $x$ \\
\hline LB & $x$ & $x$ & $x$ & $x$ & $x$ & $x$ & $x$ \\
\hline MP & $x$ & & & & $x$ & $x$ & $x$ \\
\hline ME & $x$ & & $\mathrm{x}$ & & $x$ & $x$ & $x$ \\
\hline ws & $x$ & & $\mathrm{x}$ & $\mathrm{x}$ & $x$ & $x$ & $x$ \\
\hline KV & $\mathrm{x}$ & & $\mathrm{x}$ & $\mathrm{x}$ & $\mathrm{x}$ & $\mathrm{x}$ & $\mathrm{x}$ \\
\hline
\end{tabular}

Funding This work was supported by the taskforce second victim of the Flemish Hospital Network-KULeuven \& Federal Public Service Health, Food Chain Safety and Environment of Belgium.

Competing interests None declared.

Provenance and peer review Not commissioned; externally peer reviewed.

Data sharing statement The authors make materials, data and associated protocols promptly available to others without preconditions by emailing luk. bruyneel@med.kuleuven.be.

Open Access This is an Open Access article distributed in accordance with the Creative Commons Attribution Non Commercial (CC BY-NC 4.0) license, which permits others to distribute, remix, adapt, build upon this work noncommercially, and license their derivative works on different terms, provided the original work is properly cited and the use is non-commercial. See: http:// creativecommons.org/licenses/by-nc/4.0/

\section{REFERENCES}

1. Bodenheimer T, Sinsky C. From triple to quadruple aim: care of the patient requires care of the provider. Ann Fam Med 2014;12:573-6.

2. Wu AW. Medical error: the second victim. The doctor who makes the mistake needs help too. BMJ 2000;320:726-7.

3. Edrees H, Federico F. Supporting clinicians after medical error. BMJ 2015;350:h1982.

4. Seys D, Wu AW, Van Gerven E, et al. Health care professionals as second victims after adverse events: a systematic review. Eval Health Prof 2013;36:135-62.

5. Scott SD, Hirschinger LE, Cox KR, et al. The natural history of recovery for the healthcare provider "second victim" after adverse patient events. Qual Saf Health Care 2009;18:325-30.

6. Stewart K, Lawton R, Harrison R. Supporting "second victims" is a system-wide responsibility. BMJ 2015;350, h2341.

7. Conway J, Federico F, Stewart K, et al. Respectful management of serious clinical adverse events. IHI Innovation Series white paper. Cambridge, MA: Institute for Healthcare Improvement 2011. http:// www.IHI.org.

8. Dekker S. Second victim: error, guilt, trauma and resilience. New York: CRC Press, 2013.

9. Ullström S, Sachs MA, Hansson J, et al. Suffering in silence: a qualitative study of second victims of adverse events. BMJ Qual Saf 2014;23:325-31.

10. Edrees HH, Paine LA, Feroli ER, et al. Health care workers as second victims of medical errors. Pol Arch Med Wewn 2011;121:101-8.

11. West CP, Huschka MM, Novotny PJ, et al. Association of perceived medical errors with resident distress and empathy: a prospective longitudinal study. JAMA 2006;296:1071-8.

12. Hall LW, Scott SD. The second victim of adverse health care events. Nurs Clin N Am 2012;47:383-93.

13. Seys $D$, Scott $S$, Wu A, et al. Supporting involved health care professionals (second victims) following an adverse health event: a literature review. Int J Nurs Stud 2013;50:678-87.

14. Harrison R, Lawton R, Stewart K. Doctors' experiences of adverse events in secondary care: the professional and personal impact. Clin Med 2014;14:585-90.

15. Muller D, Ornstein K. Perceptions of and attitudes towards medical errors among medical trainees. Med Educ 2007;41:645-52.

16. Waterman AD, Garbutt J, Hazel E, et al. The emotional impact of medical errors on practicing physicians in the United States and Canada. Jt Comm J Qual Patient Saf 2007;33:467-76.

17. Van Gerven E, Seys D, Panella M, et al. Involvement of health-care professionals in an adverse event: the role of management in supporting their workforce. Pol Arch Med Wewn 2014;124:312-20.

18. Burlison JD, Scott SD, Browne EK, et al. The second victim experience and support tool: validation of an organizational resource for assessing second victim effects and the quality of support resources. J Patient Saf. Published Online First: 26 Aug 2014. doi:10.1097/PTS.0000000000000129.

19. Scott SD. Three-Tiered Emotional Support System Generates Positive Feedback From Providers Who Become "Second Victims" of an Unanticipated Clinical Event. Agency for Healthcare Research and Quality: Innovations Exchange. 2010.

20. Wu AW, Steckelberg RC. Medical error, incident investigation and the second victim: doing better but feeling worse? BMJ Qual Saf 2012;21:267-70.

21. Krzan KD, Merandi J, Morvay S, et al. Implementation of a 'second victim' program in a pediatric hospital. Am J Health Syst Pharm 2015;72:563-7.

22. Pratt S, Kenney L, Scott SD, et al. How to develop a second victim support program: a toolkit for health care organizations. Jt Comm J Qual Patient Saf 2012;38:235-40.

23. Deneckere S, Euwema M, Lodewijckx C, et al. Better interprofessional teamwork, higher level of organized care, and lower risk of burnout in acute healthcare teams using care pathways: a cluster randomized controlled trial. Med Care 2013;51:99-107.

24. World Health Organization. The Conceptual Framework for the International Classification for Patient Safety. Version 1.1. Final Technical Report. 2009.

25. Thompson CV, Suggett N, Fellows J. Must "second victims" always be in the wrong? BMJ 2015;350:h2331.

26. Horowitz M, Wilner N, Alvarez W. Impact of event scale: a measure of subjective stress. Psychosom Med 1979;41:209-18.

27. Wohlfarth TD, van den Brink W, Winkel FW, et al. Screening for posttraumatic stress disorder: an evaluation of two self-report scales among crime victims. Psychol Assess 2003;15:101-9.

28. Joseph S. Psychometric evaluation of Horowitz's impact of event scale: a review. J Trauma Stress 2000;13:101-13. 
29. Thekdi SM, Milbury K, Spelman A, et al. Posttraumatic stress and depressive symptoms in renal cell carcinoma: association with quality of life and utility of single-item distress screening. Psychooncology 2015;11:1477-84.

30. Skogstad L, Hem E, Sandvik L, et al. Nurse-led psychological intervention after physical traumas: a Randomized Controlled Trial. J Clin Med Res 2015;7:339-47.

31. Carver CS. You want to measure coping but your protocol is too long: consider the Brief COPE. Int J Behav Med 1997;4:92-100.

32. Carver CS, Scheier MF, Weintraub JK. Assessing coping strategies: a theoretically based approach. J Pers Social Psychol 1989;56:267-83

33. Scheier MF, Carver CS. Optimism, coping and health: assessment and implications of generalized outcome expectancies. Health Psychol 1985;4:219-47.

34. Sorra JS, Nieva VF. Hospital Survey on Patient Safety Culture. (Prepared by Westat, under Contract No. 290-96-0004). AHRQ Publication No. 04-0041. Rockville, MD: Agency for Healthcare Research and Quality, 2004.

35. Vlayen A, Hellings J, Claes N, et al. A nationwide Hospital Survey on Patient Safety Culture in Belgian hospitals: setting priorities at the launch of a 5-year patient safety plan. BMJ Qual Saf 2012;21:760-7.

36. Meredith W. Measurement invariance, factor analysis and factorial invariance. Psychometrika 1993;58:525-43.

37. Chen FF. Sensitivity of goodness of fit indexes to lack of measurement invariance. Struct Equ Modeling 2007;14:464-504.

38. Horn JL, McArdle JJ. A practical and theoretical guide to measurement invariance in aging research. Exp Aging Res 1992;18:117-44.

39. Bauer DJ, Gottfredson NC, Dean D, et al. Analyzing repeated measures data on individuals nested within groups: accounting for dynamic group effects. Psychol Methods 2013;18:1-14.
40. Kaldjian LC, Forman-Hoffman VL, Jones EW, et al. Do faculty and resident physicians discuss their medical errors? J Med Ethics 2008;34:717-22.

41. Wu AW, Folkman S, McPhee SJ, et al. Do house officers learn from their mistakes? JAMA 1991;265:2089-94.

42. Epstein RM, Krasner MS. Physician resilience: what it means, why it matters, and how to promote it. Acad Med 2013;88:301-3.

43. Arndt M. Nurses' medication errors. J Adv Nurs 1994;19:519-26.

44. Meurier CE, Vincent CA, Parmar DG. Nurses' responses to severity dependent errors: a study of the causal attributions made by nurses following an error. $J$ Adv Nurs 1998;27:349-54.

45. Schelbred AB, Nord R. Nurses' experiences of drug administration errors. J Adv Nurs 2007;60:317-24.

46. Shanafelt TD, Balch CM, Dyrbye L, et al. Special Report: suicida ideation among American surgeons. Arch Surg 2011;146:54-62.

47. Mira JJ, Carrillo I, Lorenzo S, et al. The aftermath of adverse events in Spanish primary care and hospital health professionals. BMC Health Serv Res 2015;15:151.

48. Lewis EJ, Baernholdt M, Hamric AB. Nurses' experience of medical errors: an integrative literature review. J Nurs Care Qual 2013;28:153-61.

49. Scott SD, Hirschinger LE, Cox KR, et al. Caring for our own: deploying a systemwide second victim rapid response team. Jt Comm J Qual Patient Saf 2010;36:233-40.

50. Woodward HI, Lemer C, Wu AW. An end to the witch hunts: responding to the defenders of blame and shame. A commentary on Collins, Block, Arnold and Christakis. Soc Sci Med 2009;69:1291-3.

51. Davidson JE, Agan DL, Chakedis S, et al. Workplace blame and related concepts: an analysis of three case studies. Chest 2015;148:543-9.

52. Serembus JF, Wolf ZR, Youngblood N. Consequences of fatal medication errors for healthcare providers: a secondary analysis study. Med Surg Nursing 2001;10:193-201. 